ARTICULOS

\title{
METÁFORAS COGNITIVAS
}

\section{Una lectura de Andy Clark a la luz de "las macrosemióticas"}

\author{
Cognitive Metaphors \\ A Response to Andy Clark from Juan Samaja's “Macrosemioetics”
}

Nidia Piñeyro

(Universidad Nacional del Nordeste, Argentina)

\begin{abstract}
Resumen
En el presente artículo examino el uso de algunas metáforas cognitivas empleadas por Clark (1999) en su texto "Estar ahí. Cerebro, cuerpo y mundo en la nueva ciencia cognitiva." Parto de la noción de metáfora como argumento concreto condensado de González Asenjo (1993) e intento poner en diálogo los significados implicados en los utilizados por Clark para referirse a mente; cerebro; aprendizaje; cognición, etc. con la propuesta de una perspectiva semiótica en la investigación científica (macrosemióticas) hecha por Samaja (2004). Algunas expresiones metafóricas predilectas de Clark (como las de mente andamiada, termitero, manglares) indican su concepción estratigráfica y colectiva del esfuerzo (y los logros) epistémicos del ser humano, un ser cuya característica distintiva es la de participar de una inteligencia extendida en el tiempo y en el espacio y cuyo refinamiento y precisión están forjados en las instituciones culturales así como en el empleo de textos hablados y escritos.
\end{abstract}

Palabras clave: metáfora, cognición y macrosemióticas

\begin{abstract}
In this article I examine the use of some cognitive metaphors employed by Clark (1999) in "Being there. Brain, Body and World in the new Cognitive Science." Using Gonzalez Asenjo's (1993) notion of metaphor as "concrete condensed argument" as a starting point, I try to make Clark's implied meanings on mind, brain, learning, cognition and so on, dialogue with Samaja's (2004) semiotic perspective in scientific research ( macrosemiotics).

Some of Clark's favorite metaphors (such as scaffolded mind, nest of termites, swamps) are indexical of his stratigraphic and joint conception of human beings epistemic efforts (and assets), a being whose distinctive characteristic is that of partaking of an intelligence extended in time and space and whose subtlety and precision are forged both in the cultural institutions and in spoken and written texts.
\end{abstract}

Keywords: Metaphor, Cognition and Macrosemiotics 
"El lenguaje y el pensamiento viven una existencia simbiótica tan estrecha, nuestra manera de hablar afecta tanto nuestra concepción de lo real, que incluso la nada se concibe como una cosa."

Florencio González Asenjo.

Ontología formal de la Metáfora

\title{
1. Introducción
}

Un prejuicio extendido es considerar la metáfora o los dichos metafóricos como un recurso exclusivo del lenguaje o discurso poético. Sin embargo estas formas de expresión son muy utilizadas en el hablar cotidiano y desde siempre han sido un aliado del discurso científico para hacer comparaciones que tradujeran con mayor eficacia lo que las definiciones nominales y fórmulas dejaban a oscuras.

González Asenjo (1993) sostiene que, además de expresar creativamente la realidad, las metáforas aportan concreción, síntesis, vitalidad y compenetración máxima con la cosa referida y propone considerarlas como argumentos concretos condensados o comprimidos. El autor dice que la argumentación concreta

\begin{abstract}
...consiste en dejar que los conceptos asuman buena parte de su espectro de significaciones en vez de una sola significación invariable, y a partir de ahí sacar las consecuencias -también variables e incluso contradictorias- que esas distintas significaciones generan. (1993: 6)
\end{abstract}

En este artículo me propongo explicitar las consecuencias que a mi entender se derivan del uso de algunas expresiones metafóricas por parte de Andy Clark (1999) en su texto Estar ahí. Cerebro, cuerpo y mundo en la nueva ciencia cognitiva. No pretendo agotar el análisis de las mismas y sólo me referiré a algunas de las que son empleadas para aludir al campo de la cognición (por ejemplo, la de mente andamiada para entender la función de apoyo externo del lenguaje en la cognición; la estigmergia -propia de las termitas y otros insectos que emplean el trabajo como señal para controlar, inducir y coordinar acciones- como principio explicativo del éxito cognitivo colectivo; el tipo de relación expresada en la dupla 'la araña y su tela' para argumentar 
sobre los límites en la relación hablante-usuario / lenguaje-artefacto; la de manglar para introducir el concepto de dinámica cognitiva de segundo orden en el cual las palabras son consideradas como productoras de objetos mentales y operaciones cognitivas, etc.).

También es preciso señalar que muchas de las expresiones metafóricas halladas en esta obra son tomadas por Clark de otros científicos (por ejemplo, anadamiaje, de Lev Vygotsky.).Las mismas tienen un valor especial si pensamos en el plus conceptual que logran al ser recreadas por un autor preocupado en fundamentar un programa de investigación novedoso. Antes de pasar al desarrollo es necesario explicitar que esta lectura de Clark y la de otros autores están 'marcadas' por la visión geológica (manifiesta en la propuesta de las macrosemióticas) que Juan Samaja (2004) tiene sobre la ciencia, el proceso de investigación y el conocimiento. Esta impronta -que hunde sus raíces en la tradición dialéctica- funciona en todo momento como telón de fondo en la interpretación que propongo.

¿Qué se puede esperar de un trabajo que desarrollara las categorías implícitas en las metáforas cognitivas de un autor que trata de superar el paradigma conexionista y fundamentar las bases de otro en el que la mente sea considerada en su naturaleza corpórea y embebida? En primer lugar, un rescate del lenguaje metafórico como cantera de conceptos y argumentos eficaces para la ciencia y la comunicación académica en general. Puede ofrecer también

algunas 'pruebas' de que la producción científica (o la lógica que la rige) no es una 'flor del aire' sino que descansa en resultados (científicos y filosóficos) anteriores. Por último, algunas relaciones entre los debates actuales de las ciencias cognitivas y la epistemología como ser el papel del lenguaje natural; la escritura; la cultura y las instituciones en la cognición humana.

\section{Sobre las macrosemióticas}

\subsection{La perspectiva estratigráfica y el papel de la escritura como matriz ontológica}

Samaja (2004), al explicitar las razones de la inclusión del término macrosemiótica acuñado por Greimas (1990) para designar “dos vastos 
conjuntos de significantes" llamados "el mundo natural" y el "mundo de la lengua natural" (Greimas en Samara, 2004: 36), se da a la tarea de definir en qué consiste cada uno de ellos y de adelantar como un rasgo común el hecho de que en ninguno actúa la voluntad de los individuos. Mundo natural y lengua natural, se diferencian, sin embargo, por el tipo de significantes que constituyen sus mundos: los significantes indiciales e icónicos pertenecen a la macrosemiótica o mundo natural. Los simbólicos pertenecen a la macrosemiótica o mundo de la lengua natural e implican procesos de categorización mediados por el lenguaje. Forman parte de la macrosemiótica del mundo natural "todos los significantes indiciales e icónicos que integran el vasto mundo comunicacional de la biosfera: lo cinético, lo táctil, lo olfativo, lo gestual, lo postural, y lo proxémico...de la esfera humana anterior al lenguaje." (Samaja, 2004: 36-37) y a la macrosemiótica de la lengua natural, los significantes verbales.

Persuadido de que, aparte de estos dos, hay otros mundos de significantes con sus propias reglas, propone el ingreso en esta clasificación de "al menos dos macrosemióticas porque constituyen agregados cruciales a la comprensión de la Cultura o el Espíritu como una realidad compleja de carácter estratigráfico, conforme el modelo de la Geología." (Ibíd.: 38). Se trata de las macrosemióticas escritural y tecnoeconómica. En el juego de denominaciones que manipula y discute para la primera Samaja rechazará la de "mundo histórico" porque la expresión opaca el carácter mega-revolucionario que entraña la aparición de la escritura. El mundo escritural instaura un nuevo conjunto de significantes e inaugura una nueva ontología: " $y$ en el mismo sentido en que la lengua [...], idénticamente la escritura hace ingresar al orden del ser dimensiones ontológicas (regiones de entes) absolutamente inhallables e imposibles en un mundo sin escritura." (Ibid: 39).

Esta región de entes nuevos incluye todos los textos y todas las ciencias y según Clark, nuevos objetos mentales como los pensamientos sobre el pensar. Esta afirmación se funda, entre otras razones, en el trabajo de Merlín Donald (1991) quien en un estudio exploratorio sobre la evolución de la cultura y la cognición reconoce dos tipos de sistemas externos de memoria: uno mítico y otro teórico. El segundo, el de la escritura representa " [...] 'mucho más que una invención simbólica, como el alfabeto, o que un soporte específico de memoria 
externa [...], lo que se creó fue el proceso de descubrimiento y cambio cognitivo externamente codificados' ." (1991: 343)1.

En relación con 'el pensar sobre el pensar' o dinámica cognitiva de segundo orden, trabajaremos en otro tramo del texto, cuando nos aboquemos a las consecuencias de tratar el lenguaje (escrito y hablado) como generador de nuevos paisajes ontológicos y como equivalente a la dinámica de generación de los manglares. Baste por ahora señalar que, como Samaja, Clark sostiene con vehemencia que la capacidad de hacer ciencia no depende directamente de los 'pertrechos' biológicos como de los culturales, en especial de los que permiten codificar, congelar y autoevaluar los pensamientos.

El hecho de que los seres humanos puedan hacer lógica y ciencia no implica que el cerebro contenga un auténtico instrumento lógico o que codifique teorías científicas con un formato similar a la expresión habitual mediante palabras y frases. En realidad, tanto la lógica como la ciencia se basan en gran medida en el empleo y la manipulación de medios externos, especialmente los formalismos del lenguaje y la lógica, y las capacidades de almacenamiento, transmisión y refinamiento proporcionadas por las instituciones culturales y el empleo de textos escritos y hablados. (1999:278)

Los escalones de la pirámide o las capas estratigráficas aparecen con más claridad: primero el mundo natural, luego el de la lengua natural, luego el de la escritura. Cada uno de los niveles guarda con el anterior una relación de dependencia y con el posterior una relación de subordinación. ¿Cómo es la macrosemiótica que depende de la escritural, su matriz ontológica, -y de las otras anteriores- para existir?

\subsection{La ciencia como metalenguaje y las instituciones académicas como termiteros}

Pareciera que estamos en condiciones de adentrarnos en la caracterización de lo que Samaja denomina la macrosemiótica tecnoeconómica (o lenguaje de los objetos construidos o del mundo artificial-virtual). A ella pertenecen los

'lenguajes' empotrados en las técnicas [...] $<y>$ todos los metalenguajes que contienen y especifican cánones y patrones de validación de los saberes sociales y de las Lenguas mismas

\footnotetext{
${ }^{1}$ Citado por Clark (1999:61).
} 
por medio del control de los objetos de aplicación mediante vínculos contractuales y constructivos. (2004: 24)

Tal como el lenguaje hablado y la escritura, a su turno, el trabajo científico crea una región especial de significados y realidades. Sus productos semióticos se gestan y circulan e interpretan y validan en espacios restringidos, aunque para salir a la luz se nutran de la gran cantera del mundo social y natural y el efecto de su manipulación se expanda más allá de los claustros, departamentos de investigación, universidades, etc.

El hecho de que los resultados del saber científico son considerados por Samaja (2004:23 -24) como un 'tesoro' de poco más de 200 años nos debe alertar sobre dos cuestiones: en perspectiva geológica, estamos frente a un mundo flamante... pero aún cerrado. El tesoro "está acumulado en sus tradiciones epistémicas y tecnológicas [...] que las sociedades burguesas preservan y transmiten mediante sus diversos dispositivos formadores [...]." Si bien el autor nos aclara que "existe de manera práctica en las rutinas del mercado y de las restantes instituciones de la sociedad civil" no podemos decir que exista legítimamente (o sea legitimante producirlos) en otros espacios.

Dicho esto (y a los efectos de no soslayar el aspecto político que entraña la cuestión), asumo como un hecho que las instituciones académicas o las comunidades de especialistas, la corporación científica o los investigadores, a secas, poseen y son portadores de un determinado estilo cognitivo que se trasluce en sus prácticas metodológicas, en su forma de argumentar, en sus textos. Ser parte de una comunidad científica supone ciertos 'modos o énfasis' aceptados y transmitidos por las disciplinas. Zurita (2007) ${ }^{1}$ lo expresa de la siguiente manera:

Aunque las modalidades cognitivas nucleares del pensamiento científico son comunes a sus diversos espacios de realización, los énfasis en los tipos de operaciones de razonamiento y las formas que adoptan, difieren de un dominio disciplinar a otro. Cabe suponer que estos énfasis y particularidades, que se expresan en los modos aceptados por las comunidades científicas para el descubrimiento y la validación se entretejen con epistemologías tácitas o explícitas que el estudiante internalizará con mayor o menor coherencia y aceptación,

\footnotetext{
${ }^{1}$ Ver CORRAL DE ZURITA, N. (2007): Habilidades de razonamiento y creencias epistemológicas de estudiantes universitarios avanzados en contextos académicos - disciplinares. (Proyecto de investigación acreditado ante la Secretaría General de Ciencia y Técnica de la Universidad Nacional del Nordeste), p. 3 y ss.
} 
creencias que a su vez influirán en su modo de aproximarse al aprendizaje. (2007: 3)

Digamos que, además de ser un espacio restringido, el científico posee en su interior otra serie de cercos o sesgos y que los mismos tienen su origen en las tradiciones disciplinares. Clark no entra centralmente en la cuestión, sin embargo, su reflexión sobre el aprendizaje colectivo aporta una interesante explicación del por qué las tradiciones son alimentadas y mantenidas por los grupos de profesionales científicos (humanos, al fin). Me refiero a su argumentación sobre la naturaleza económica de nuestro sistema de cómputos que rige el cerebro biológico, la cual impone al ser humano una suerte de ‘tercerización' de algunas operaciones mentales tales como las formas de razonar:

\begin{abstract}
la idea es que la cognición avanzada depende de manera crucial de nuestras capacidades para disipar razonamiento: para difundir a través de estructuras sociales complejas el conocimiento y la sabiduría práctica que adquirimos y para reducir las cargas de los cerebros individuales situando estos cerebros en complejas tramas de restricciones lingüísticas, sociales, políticas e institucionales. (1999: 234)
\end{abstract}

Puesto así pareciera que en los aprendizajes disciplinares, como en otros aprendizajes prácticos, somos proclives a aprovecharnos de los modos y los énfasis establecidos (y exitosos) como estrategia de descompresión a la carga computacional. Clark, va abordar el asunto a partir de una metáfora incisiva: los humanos nos parecemos bastante a ciertos insectos sociales de pistas químicas...No somos termitas pero nos parecemos en algunos cuantos aspectos. Éstas y otras metáforas referidas a la cognición serán analizadas en los parágrafos siguientes.

\title{
3. Las metáforas cognitivas en Clark: de bisagras, umbrales y miradores
}

En la introducción a este artículo adelanté mi intención de examinar algunas metáforas cognitivas en un marco más general, el de la aproximación al entendimiento de la ciencia, el conocimiento y la investigación en clave dialéctica. 
También señalé que una de las razones por las cuales las metáforas de Clark resultan interesantes para este propósito radica en que es un autor en busca de los cimientos (que en ciencia, siempre son argumentos) para un nuevo programa de investigación en ciencias cognitivas. Este esfuerzo, idéntico al que encara Samaja desde otros lugares -también transdisciplinarios-, nos hace pensar que las metáforas en tanto argumentos concretos condensados serán fértiles para pensar algunas cuestiones nodales que impregnan el debate de las ciencias de la cognición que estamos transitando.

En síntesis, intento sugerir que cuando leamos, andamios, termiteros, manglares o arañas con telarañas, estemos dispuestos a aceptar que, la mayoría de las veces, las metáforas son un instrumento para conceptualizar y persuadir al mismo tiempo. En este caso, el esfuerzo de persuasión está orientado a convencernos de que los argumentos implicados por las metáforas tradicionales ofrecen un flanco para introducir algunos interrogantes sobre su eficacia explicativa. Creemos que las de Clark tienen todos los ingredientes que, según Gonzalez Asenjo (1993), deberían tener las buenas metáforas: incisividad, pertinencia y adecuación a la realidad que esperan representar.

\title{
3.1. Mentes con andamiajes
}

Clark introduce la noción de andamiaje aclarando su filiación con la psicología del desarrollo:

\begin{abstract}
la noción de andamiaje tiene sus raíces en el trabajo del psicólogo soviético Lev Vigotsky [...] quien destacó que la experiencia con estructuras externas puede alterar y dar contenido a los modos de procesamiento y comprensión intrínsecos de un individuo. (1999:86).
\end{abstract}

El vuelo que le imprimirá hará que la metáfora del andamio se expanda hacia otros tipos de apoyos o ayudas externas que exceden la que puede brindar un adulto como guía en el aprendizaje de un niño o la estructura que por fuera nos brindan el lenguaje y otros elementos del entorno: "la noción intuitiva de andamiaje es más amplia porque puede abarcar toda clase de ayudas externas, tanto si proceden de adultos como del entorno inanimado." (ibid: 87)

La primera categoría implicada en esta metáfora puede expresarse con la idea de insuficiencia. Algo que precisa un andamio es algo en construcción, 
demasiado frágil, inseguro o dependiente como para estar erguido sin ayuda. La otra categoría que emerge con toda claridad es la de externalidad de la solución a la insuficiencia. Los andamios van por fuera de la estructura que ayudan a sostener. El salto que da Clark parado sobre los hombros de la metáfora vygostkyana supone que los adultos y el lenguaje público son sólo un tipo de los muchos apoyos externos de que el ser humano puede valerse para conocer y operar en el mundo. Incorpora así, una serie de apoyos externos nuevos que colaboran para que un ser cuya mente es "corta de vista; especializada e internamente fragmentada" adquiera máxima coherencia y utilidad. (ibid., 72).

Los tipos de apoyo que imagina Clark, además del habla privada y la acción andamiada -de cuño vygotskyano- van desde el empleo de instrumentos (lápiz y papel, por ejemplo) hasta la explotación del conocimiento y las aptitudes de otras personas; "el concepto de andamiaje (tal como yo lo utilizaré) abarca una amplia clase de potencialidades físicas, cognitivas y sociales que nos permiten alcanzar una meta que, en caso contrario, sería inalcanzable." (1999, 256)

Los andamios son clasificados según un criterio de complejidad ascendente: en los casos más simples encontramos el empleo de soportes externos de símbolos, sirven para descargar parte de nuestra memoria en el mundo. A este grupo de soportes artificiales pertenecen las agendas, diarios personales, libretas, etc. Un caso más complejo es el empleo de etiquetas. Son útiles para simplificar el entorno, nos permite hallar objetivos en escenarios nuevos sin necesidad de conocer previamente qué debemos buscar o dónde. A este grupo pertenecen los carteles y avisos en las carreteras, por ejemplo, y lo que se logra es descargar la carga computacional y la necesidad de hacer inferencias. El tercer lugar lo ocupa el uso de etiquetas lingüísticas. Vuelven más simple el entorno de aprendizaje de ciertos conceptos importantes permitiendo comprimir enormes espacios de búsqueda hasta un tamaño manejable. A este grupo pertenecen los conceptos que permiten incorporar otros de su misma naturaleza, función o estructura activando una serie de asociaciones que viabiliza la aprehensión en estado de ausencia del objeto nuevo. Por último Clark señala el empleo del lenguaje para coordinar la acción. Entre sus beneficios se encuentran la minimización del esfuerzo por vía de la planificación explícita (personal o interpersonal). Lo que se logra mediante un plan es la 
reducción de las deliberaciones en línea. Ejemplos de estos usos son la planificación de acciones individuales o colectivas que se organizan en una determinada secuencia y, que al adquirir estabilidad restringen la necesidad de decidir sobre cada evento de la cadena.

Volviendo al asunto de las categorías implicadas en la metáfora de andamiaje, queda por decir, que la tercera es la de interacción colaborativa entre la mente y el entorno. ¿Cuál es el tipo de intercambio que se realiza entre el organismo vivo y su ambiente o cómo lo beneficia en tanto andamio?

\begin{abstract}
El flujo de pensamiento [...] consiste en transformar entradas, simplificar búsquedas contribuir al reconocimiento, estimular el recuerdo asociativo, descargar memoria; etc. En cierto sentido, un ser humano que razona es un dispositivo cognitivo verdaderamente distribuido: realiza llamadas a recursos externos para que lleven a cabo unas tareas de procesamiento específicas [...] El flujo de pensamientos o la generación de respuestas razonadas no son un mérito exclusivo del cerebro. La colaboración entre cerebro y mundo es mucho más rica y está más impulsada por necesidades de computación e información de lo que se creía hasta ahora. (Ibíd. 110)
\end{abstract}

Todas estas categorías: insuficiencia, solución externa a la insuficiencia de cuya cuasi-duplicación encontramos los ecos en la de interacción colaborativa- serán las bases de un remate difícil de rechazar: "el verdadero motor de la razón no está limitado ni por la piel ni por el cráneo.”(Ibíd.:111)

Esta metáfora de la mente andamiada es recurrente y aparece en la obra mucho antes de que el autor se encargue específicamente de los andamiajes por excelencia: el cultural y el lingüístico previstos para los dos últimos capítulos. Cuando leemos los títulos en 2.5 "Mentes con andamiajes"; en 3.3. "Apoyarse en el entorno" para, finalmente, encontrarnos con la metáfora humana de “cerebros salvajes, mentes andamiadas" (en 9.1.) empezamos a pensar que, tal vez, es eso lo que verdaderamente somos: una simbiosis entre cuerpo, mente y entorno.

\title{
3.2. Algoritmos estigmérgicos y cognición humana colectiva: no somos termitas, pero...
}

Clark (1999:118) -también en una parte distante del desarrollo de los andamiajes culturales y lingüísticos- nos ofrece una definición etimológica de estigmergia: "una combinación de estigma (señal) y ergon (trabajo) implica la 
utilización del trabajo como señal para más trabajo” y la va a ligar a los argumentos esgrimidos para explicar el éxito del aprendizaje o los aprendizajes colectivos, propios de los seres humanos. Nos adelanta de inmediato que la verdadera estigmergia "requiere una falta total de flexibilidad de respuesta en presencia de una condición desencadenante. Por tanto, la actividad humana en general, sólo es cuasi estigmérgica.”(Ibíd.:119).

Aún así, avanzará en la analogía, sumando argumentos a favor de la posible naturaleza estigmérgica del aprendizaje en las comunidades humanas.

\begin{abstract}
Naturalmente, aunque los seres humanos se encuentran inmersos en los entornos restrictivos de grandes instituciones sociales, políticas o económicas, ino son termitas!. [...] Sin embargo, nuestros éxitos (y a veces nuestros fracasos) colectivos se suelen comprender mejor si consideramos que el individuo sólo elige sus respuestas dentro de las limitaciones -con frecuencia poderosas- impuestas por los contextos de acción más amplios de carácter social e institucional. Y de hecho esto es justamente lo que cabe esperar cuando reconocemos que la naturaleza computacional de la cognición individual no es ideal para abordar ciertos ámbitos complejos (Ibíd.: 240-241)
\end{abstract}

Pero ¿qué nos presenta a primera vista un termitero si no estuviéramos informados de la estigmergia que rige su dinámica? En primer lugar que es un espacio artificial o creado por muchos individuos. En segundo lugar, (y esto ya es una inferencia) que los individuos deben haber coordinado sus acciones. En tercer lugar, que un individuo solo, difícilmente, podría haberlo logrado. Si ponemos estos primeros rasgos del termitero en diálogo con los argumentos implicados en la metáfora del andamiaje, nos daremos cuenta de que Clark está proponiendo una suerte de sistema de metáforas y no metáforas sueltas con una mera intención estilística.

Atendiendo a la cuestión más explícita, la de la estigmergia, la primera categoría que se nos presenta como nítida es la capacidad del trabajo como señal para generar más trabajo. Es decir, el empleo de la acción como señal para instigar la acción. Para sostener esta idea, Clark propondrá otra metáfora anexa; la de un campus hipotético en construcción y que aún no tiene senderos y cuyos planificadores deciden dejar librado su trazado al uso 'espontáneo' de los usuarios. A través de ella, ingresa, sutilmente al ámbito de las acciones humanas referidas a la resolución de problemas y que explotan la coordinación y el esfuerzo de una comunidad para lograr el éxito. 
[...] en ocasiones podemos estructurar nuestro entorno de resolución de problemas como una especie de subproducto de nuestra actividad básica de resolución de problemas. En nuestro campus hipotético, los primeros viandantes estructuran el entorno como un subproducto de sus propias acciones, pero los viandantes posteriores se encontrarán con un entorno estructurado que, a su vez, puede ayudarles a resolver, precisamente, los mismos problemas." (Ibíd: 123)

Clark destacará el hecho de que "los sistemas < teóricos> clásicos omiten la tendencia dominante en los agentes humanos a estructurar activamente su entorno con el fin de reducir posteriores cargas computacionales.” (1999: 201). Reforzará así otra categoría presente en su metáfora básica, la del termitero: el trabajo colectivo ahorra trabajo individual, solidaria también con la metáfora anterior de los andamiajes externos.

\begin{abstract}
Cuando hacemos esto, añadimos estructura a nuestro entorno de una manera diseñada para simplificar posteriores conductas de resolución de problemas, de manera muy parecida al empleo por parte de ciertos insectos sociales de pistas químicas que añaden a su entorno local una estructura fácil de utilizar y que les permite hacer que el camino hasta el alimento sea detectable con un gasto computacional mínimo (1999, 201)
\end{abstract}

Pero el remate llega en oleajes. Las características de las acciones realizadas en el termitero en relación con las que los humanos pudieran realizar para resolver algunos problemas de diseño del entorno no son tan incisivas como la propuesta de entender las instituciones sociales como productoras de señales para regular las conductas de los individuos.

En resumen [...] los seres humanos, destacamos en un aspecto crucial: somos expertos en estructurar nuestros mundos físicos y sociales y en extraer conductas complejas y coherentes de estos recursos tan difíciles de controlar. Empleamos la inteligencia con el fin de estructurar nuestro entorno para poder tener éxito con menos inteligencia. iNuestros cerebros hacen que el mundo sea inteligente para que nosotros podamos ser unos tontos felices! O dicho de otra manera, el cerebro humano más estas piezas de andamiaje externo son los que finalmente constituyen la máquina de inferencias racional e inteligente que llamamos mente. Vistas así las cosas, está claro que somos inteligentes; sin embargo, nuestros límites se adentran en el mundo mucho más de lo que inicialmente pudiéramos suponer. (1999: 234)

Sabiendo que el examen hecho hasta aquí no agota en absoluto la riqueza de las categorías implicadas en el uso de la metáfora del termitero, y por las razones de extensión de este trabajo, seleccioné algunos párrafos que contienen una versión más categórica en relación con los aprendizajes colectivos y que según creo, abonan una serie de debates más sociológicos o político 
institucionales del mundo académico en tanto corporación. Me refiero al papel de las instituciones académicas y dispositivos de formación en general en la adquisición de modelos cognitivos por parte de sus discípulos más jóvenes.

En primer lugar tomaría nota del argumento de "determinación ecológica" de las funciones de diversos estados y procesos internos, la cual indica que "la situación del organismo en un entorno más amplio y sus interacciones con ese entorno influyen en lo que se debe representar y cómo computar internamente. (1999;146)

En segundo término, vale poner en esta misma línea el argumento sobre el "carácter oportunista de gran parte de la cognición biológica."

Cuando el cerebro biológico se enfrenta a las fuertes limitaciones temporales propias de la acción en el mundo real y sólo dispone de un estilo de cómputo incorporado bastante restrictivo y orientado a la compleción de patrones, aceptará toda la ayuda que pueda conseguir. Esta ayuda incluye el empleo de estructuras físicas externas (tanto naturales como artificiales), el empleo del lenguaje y de instituciones culturales y el empleo abundante de otros agentes. (1999: 123)

Por último, y más específico aún, el argumento de la utilización del saber adquirido que portan las instituciones y que son empleadas por los humanos como un recurso externo para sus necesidades cognitivas:

\begin{abstract}
En esos ámbitos, la resolución cotidiana de problemas suele suponer el empleo de estrategias de reconocimiento de patrones localmente eficaces que se invocan como resultado de alguna incitación externa y que dejan huellas en forma de otras señales que estarán disponibles para manipulaciones futuras dentro del engranaje más amplio de la institución. [...] gran parte de lo que sucede en el complejo mundo de los seres humanos se puede comprender, de una manera un tanto sorprendente, como si implicara algo semejante a los algoritmos estigmérgicos. (1999: 240)
\end{abstract}

Recordemos que la estigmergia supone el empleo de estructuras externas para controlar, inducir y coordinar acciones individuales. Al parecer, muchos de los modos y énfasis disciplinares reconocibles en modelos argumentativos, en el uso preferencial de algunos tipos de razonamiento o la escritura misma de los textos, se pueden explicar por los argumentos de determinación ecológica, el carácter oportunista de la cognición biológica, y por la estigmergia característica de algunas estructuras sociales, que puedan inducir y coordinar una larga sucesión de episodios de resolución de problemas, conservando y transmitiendo las soluciones parciales a lo largo de la sucesión.” (1999,-241) 
Podría ser, como lo expresa Hutchins $(1995)^{1}$, que estas características (y la del acostumbramiento a una interpretación de la entrada y la dificultad para su posterior abandono) "concuerda bastante bien con el familiar efecto psicológico del sesgo a la confirmación, es decir, la inclinación a desatender, descartar o reinterpretar de una manera creativa las pruebas que van en contra de alguna hipótesis o modelo que ya se haya establecido." (ibid:242)

\subsection{Dinámica cognitiva de segundo orden: el lenguaje como manglar}

Es posible que la metáfora más atractiva de Clark para quienes nos dedicamos al estudio del lenguaje sea la que sugiere que su función primordial es la de realizar una operación cognitiva específica, la de generación de objetos mentales imprescindible para la acción en el entorno. Sin embargo, esta metáfora -tal como lo propongo en otra parte de este texto- forma parte de un sistema de argumentos condensados concretos cuya función es facilitar la incorporación de una nueva concepción de la mente, un sistema que opera en colaboración y que potencia sus habilidades biológicas explotando todo tipo de apoyos físicos $\mathrm{y}$ sociales.

En este marco, no sorprende la elección de la imagen de manglar. Este tipo especial de formación vegetal contiene gran parte de las claves para comprender cómo el contenido de nuestro pensamiento -en gran parte lingüístico- no sólo depende de las palabras sino que ellas mismas atraen, fijan y elaboran y controlan otros objetos mentales no lingüísticos. Pero la relación no es automática. Es efectiva en la medida que Clark la desglosa. El autor decide ofrecer, la definición nominal por delante de la expresión metafórica que en este caso cumple la función de ilustrar el argumento de una manera más vívida y concreta.

Denomino dinámica cognitiva de segundo orden a un cúmulo de capacidades que implican autoevaluación, autocrítica y respuestas compensatorias ajustadas con precisión. Esto es lo que ocurre cuando reconocemos un defecto en uno de nuestros planes o argumentos y dedicamos recursos cognitivos a eliminarlos o cuando reflexionamos sobre la poca fiabilidad de nuestros juicios iniciales en ciertos tipos y, como resultado, actuamos con cuidado especial, o cuando averiguamos por qué hemos llegado a una conclusión determinada

\footnotetext{
${ }^{1}$ Citado por Clark (1999:242).
} 
comprendiendo las transiciones lógicas de nuestro propio pensamiento, o cuando descubrimos las condiciones bajo las cuales pensamos y tratamos de provocarlas.

En este modelo, el lenguaje público y la repetición interna de oraciones actúan como las raíces aéreas de un mangle: las palabras actuarían como puntos fijos capaces de atraer y acumular más material intelectual, creando las islas de pensamiento de segundo orden tan características del paisaje cognitivo del Homo sapiens. $(1999,264)$

Ahora podemos desarrollar mejor las categorías implicadas en la metáfora. La primera que se nos aparece es la de la naturaleza procesual de su formación. Como en el caso de los manglares, la repetición es la condición para la estructuración posterior.

La segunda característica es la de que el resultado de este proceso repetido es la formación de una estructura estable y la tercera, es que esa estabilidad (en el agua, en la mente) funciona como un atractor de otros materiales intelectuales que se adhieren a la estructura: "El proceso de formulación lingüística crea una estructura estable a la que se adhieren pensamientos posteriores" (ibid: 264)

La naturaleza de estos pensamientos posteriores -ya previstos en la tesis vygotskiana del papel del habla interna- es de un nivel más elevado. Cumplen la función de control sobre el material sedimentado (otros pensamientos) que si estuvieran a la deriva (no estructurados en formulaciones lingüísticas recordables), no podrían ser revisados en sus detalles. "El lenguaje se revela como un recurso fundamental mediante el cual redescribimos con eficacia nuestros propios pensamientos en un formato que los hace asequibles para una variedad de nuevas operaciones y manipulaciones. (1999: 266)

Tengo la impresión de que esta noción puede ser mucho mejor explotada en la reflexión sobre el papel del lenguaje como 'máquina cognitiva'. Intuyo que muchas lecturas que ahora me resuenan (la de Peirce, por ejemplo) pueden enriquecer la tarea de hacer justicia a esta metáfora que propone Clark. Pero el esfuerzo necesario excede el propósito de este trabajo. A los efectos de ver cómo Clark legitima su tesis, creo que la explicación del uso del manglar pudo haber cumplido su cometido. 


\section{4. “¿Dónde acaba el usuario y empieza el instrumento?” La araña y su tela}

Para finalizar, he seleccionado la metáfora de la araña y su tela como argumento del tipo de relación que existe entre el lenguaje y el ser humano. Como puede verse en el título de este apartado Clark hace funcionar esta metáfora como una respuesta a una pregunta sobre los límites entre el usuario (hablante) y el instrumento (lenguaje). De entre las respuestas posibles (el límite es X; no hay límite; la idea de límite no es pertinente, etc.), el autor contesta con un rodeo: no es que no haya límite pero la relación es tan íntima, el lenguaje es tan omnipresente, el usuario lo necesita tanto.... ique es como si se tratara de la relación que guardan la araña y su tela!

Antes de pasar a las categorías es necesario contextualizar el uso de esta expresión. Estamos en el último capítulo del libro, hablamos del lenguaje como un artefacto definitivo (otra metáfora) y la cuestión de los límites es central para la tesis de la mente embebida y corporeizada. Se nos está proponiendo la necesidad de distinguir entre acciones pragmáticas y acciones epistémicas, éstas últimas tienen el objetivo de alterar las tareas computacionales a las que se enfrenta el cerebro cuando trata de resolver problemas (271). El lenguaje, es justamente el instrumento que permite acciones de esta naturaleza. Es una extensión cognitiva. Pero ¿̇cuál es su especificidad?

\footnotetext{
El flujo del razonamiento y el pensamiento, y la evolución en el tiempo de las ideas y las actitudes, están determinados y explicados por la interacción íntima, compleja y continua entre cerebro, cuerpo y mundo. [...] ¿Qué distingue los casos más convincentes de la existencia de una sólida extensión cognitiva de otros casos? (1999: 274)
}

Clark enumera y revisa algunas características importantes de los casos convincentes: accesibilidad (siempre está ahí y la información que contiene es fácil de encontrar y utilizar); refrendo automático o función explicativa codificada como en la memoria a largo plazo (esta información se acepta automáticamente); hecho a medida (la información ha sido recopilada $\mathrm{y}$ corroborada por el propio usuario).

Dicho esto, aparecen con nitidez las características de la metáfora puestas en juego. Es hora de rematar: 
[...] la imagen general es la de una relación usuario - artefacto bastante especial donde el artefacto siempre está presente, se utiliza con frecuencia, está hecho 'a medida' del usuario y éste tiene una profunda confianza en él. [...] los límites del yo -y no sólo los de computación y del proceso cognitivo general - solo amenazan con extenderse hacia el mundo cuando la relación entre el usuario y el artefacto es casi tan estrecha e íntima como la que existe entre la araña y su tela.” (274)

Pero esta metáfora, aunque a primera vista nos resulte autónoma, es parte de una cadena argumental que no pierde sus perfiles y objetivos. Por un lado refuerza la inmediatamente anterior del lenguaje como artefacto; por otro, le permite cerrar la propuesta conceptual más medular de toda la obra:

\begin{abstract}
En resumen, [...] afirmo que, como mínimo, tenemos buenas razones explicativas y metodológicas para aceptar en ocasiones una noción bastante liberal del alcance de los procesos cognitivos y computacionales que permita explícitamente la diseminación de estos artefactos por el cerebro, el cuerpo, el mundo y los artefactos. Entre estos artefactos destacan las diversas manifestaciones del lenguaje público. El lenguaje es, en muchos aspectos, el artefacto definitivo: es tan omnipresente que casi es invisible y su carácter es tan íntimo que no está claro si es un instrumento o una dimensión del usuario. Cualesquiera sean los límites, como mínimo nos enfrentamos a una economía estrechamente vinculada donde el cerebro biológico está increíblemente potenciado por algunas de sus creaciones más extrañas y recientes: palabras en el aire, símbolos en páginas impresas. (275)
\end{abstract}

\title{
4. A manera de conclusión: la mente como caja de sorpresas
}

Creo que para concluir el trabajo valdría la pena decir una vez más que las metáforas cognitivas en la obra de Clark forman un sistema en que cada una de ellas se acopla a las demás compartiendo argumentos que tejen una explicación de otro nivel, lo que yo interpreto como su tesis central. Es justo a estas alturas, dedicar unas líneas a la especulación sobre el sistema de metáforas que éste sistema confronta. Me refiero a las expresiones consagradas por las tesis que Clark desea poner en cuestión.

Una de ellas, es la del cerebro como ejecutivo central cuya consecuencia más palpable es la de aceptar el límite nítido entre el pensador y su mundo. A esta manera de concebir el cerebro Clark le opone, además de las analizadas aquí, otras como: 'cerebros salvajes, mentes andamiadas'; y la mente como 'caja de sorpresas'. 
Me detendré en esta última porque la oposición tajante permite hacer un cuadro comparativo imaginario de dos modelos de mente diferentes que representan tradiciones enfrentadas.

Esta expresión es la síntesis de una propuesta diferente a la versión tradicional que considera la distinción entre percepción, cognición y acción y reniega del papel central de los andamios sociales en la cognición. Esta caja de sorpresas debe interpretarse como la antítesis de la planificación y su consecuente simplicidad como principio explicativo para la complejidad que entraña la cognición de los seres con mente. Esta caja está "repleta de agencias internas, cuyos papeles computacionales se suelen describir mejor incluyendo características al entorno local." (:279).

Por último, Clark agrega a su metáfora final de la mente una conclusión contundente que abre el camino para reformular interrogantes y para pensar nuevas metodologías que den cuenta de la complejidad del objeto de estudio de las ciencias cognitivas:

Con la desaparición del ejecutivo central, la percepción y la cognición parecen más difíciles de distinguir en el cerebro. Y la división entre pensamiento y acción se hace añicos en cuanto reconocemos que las acciones en el mundo real suelen desempeñar, precisamente, los tipos de funciones que más se suelen asociar con los procesos internos de cognición y computación (279)

Resta señalar cómo se vinculan estas metáforas en su conjunto con la propuesta estratigráfica que hace Samaja al definir las cuatro macrosemióticas.

En primer lugar parece muy clara la correspondencia entre la idea de matriz ontológica de los sistemas de signos expuesta por Samaja en la descripción de la segunda y tercera macrosemióticas y las metáforas de andamio y de manglar de Clark. Esto es, la capacidad del lenguaje para crear entes y constelaciones de entes que no podrían existir sin su intermediación. En Clark esta tesis se sostiene, además, en relación con el carácter de artefacto definitivo del lenguaje expresado en la metáfora de la araña y su tela.

El 'pensar sobre el pensar' o dinámica cognitiva de segundo orden, propuesto por Clark por medio de la metáfora del mangle, se complementa con otra figura: la del termitero. La misma dialoga muy bien con el tratamiento que hace Samaja de la ciencia como metalenguaje. Lo que Samaja selecciona como 
rasgo de la cuarta macrosemiótica, la tecnoeconómica, es la capacidad del trabajo científico para crear una región especial de significados y realidades pero también para orientar la acción cognitiva de los miembros de la comunidad científica. La misma noción es desarrollada por Clark para argumentar sobre la cuasi estigmergia de las instituciones de formación cuya premisa puede sintetizarse en que el trabajo colectivo ahorra trabajo individual. De allí que la utilización del saber adquirido que portan las instituciones son empleadas por los miembros más jóvenes de la comunidad como un recurso externo para descomprimir sus requerimientos cognitivos.

Las nociones anteriores ofrecen una versión formativa de la subjetividad humana, la cual, sostiene Samaja, nos permite primero percibir, después hablar, luego escribir y luego (y como consecuencia de todo eso) hacer ciencia. Este enfoque estratigráfico está presente también en Clark. Estos escalones de la pirámide o las capas geológicas pensadas por Samaja aparecen una y otra vez en el texto del segundo. Así, la función primordial del lenguaje que es la de realizar una operación cognitiva específica (generar objetos mentales imprescindible para la acción en el entorno) se domicilia en un ser vivo dotado de un cerebro restringido y fragmentado que alcanza dimensión humana cuando reparte los insumos que requiere en instituciones socio culturales. $\mathrm{Si}$ bien Clark no adopta la analogía de estratos, al igual que Samaja, no arroja ideas sueltas sino que las integra en un sistema de metáforas que, en su caso, funcionan como un dispositivo que facilita la incorporación de una nueva concepción de la mente: un sistema que opera en colaboración y que potencia sus habilidades biológicas explotando todo tipo de apoyos físicos y sociales.

La naturaleza procesual de la formación del conocimiento, el origen escritural de la ciencia, el papel del entorno social en el desarrollo de las funciones cognitivas, la importancia de las extensiones de la mente en nuestros artefactos pernean la obra de ambos autores y aportan argumentos afines para los debates actuales de las ciencias de la cognición. ${ }^{\text {|का }}$ 


\section{REFERENCIAS BIBLIOGRÁFICAS}

CLARK, A. (1999): Estar ahí. Cerebro, cuerpo y mundo en la nueva ciencia cognitiva. Paidós; Barcelona.

CORRAL DE ZURITA, N. (2007): Habilidades de razonamiento y creencias epistemológicas de estudiantes universitarios avanzados en contextos acdémicos - disciplinares. (Proyecto de investigación acreditado ante la Secretaría General de Ciencia y Técnica de la Universidad Nacional del Nordeste).

GONZÁLEZ ASENJO, F. (1993) “Ontología Formal de la Metáfora.” En: Escritos de Filosofía $\mathrm{N}^{\mathrm{o}} 23$ - 24. Buenos Aires.

SAMAJA, J. (2004) "Para una Mirada Panorámica del Proceso de la Investigación Científica en la Perspectiva Semiótica.” En: Proceso, Diseño y Proyecto en Investigación Científica. (Primera Parte.), JVE; Buenos Aires.

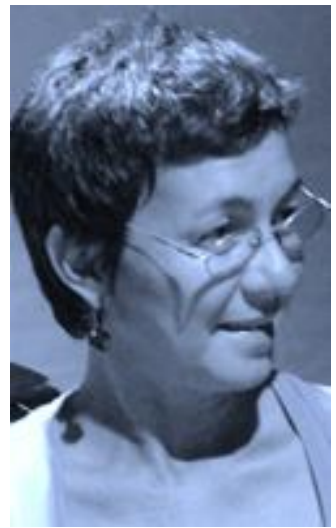

Nidia Piñeyro es Profesora en Letras, Especialista y Magíster en Desarrollo Social. Se desempeña como docente regular por concurso en la Facultad de Humanidades en la Universidad Nacional del Nordeste en las Cátedras de Introducción a las Ciencias Sociales y Teoría y Métodos de la Investigación, en el Departamento de Ciencias de la Educación. Autora de un libro en co-autoría, de varios capítulos en libros y de artículos relacionados con el lenguaje y la subjetividad. Se dedica al análisis del discurso aplicado a problemas de la política, la economía, el ambiente y el conocimiento. Es estudiante del Doctorado en Ciencias Cognitivas de la Universidad Nacional del Nordeste. 